\title{
Exploring Mental Health Disorders and Creativity
}

Olivia Silverstone

In some people with mental health disorders, creativity can be an associated characteristic that is displayed through artistic output. As stated by Sussman (2007), "a link between mental illness and creative output has been documented throughout history" (p. 21). Because of the increasingly high incidence of mental disorders prevalent in today's society, "all Canadians [are affected] through mental illness in a family member, friend, or colleague" (Halter \& Haase, 2014, p. 10). Creativity "is the ability to produce work that is both novel (i.e., original or unexpected) and appropriate (i.e., useful or meets tasks constraints" (Sternberg \& Lubart, 1996, p. 677). Although mental disorders can clearly cause significant impairments to many individuals, it is important to recognize that, at times, their presence could possibly enhance the abilities for certain individuals. Thus, it is important to recognize that "creativity is enhanced in specific mental disorders" (Kyaga et al., 2011, p. 373). The purpose of this paper is to examine the degree to which there is a link between people with mental health disorders and creative genius, as well as the therapeutic effects of creative activities in daily living. Some of the most creative people throughout history have experienced a mental disorder. Whether the two characteristics are related and, if so, how, is a great conundrum. It is important for nurses to encourage and acknowledge creativity in all clients, but especially essential for persons with mental disorders.

There are many famous individuals throughout history who suffered from mental illness yet were also very well recognized for their creative contributions to society. Sample (2015), recognizes that mental disorders and "creativity [have] given us Mozart, Bach, [and] Van Gogh" (para. 8) as major original

Vol. 4(1) | DOI: https://doi.org/10.31542.muse.v4i1.865 MacEwan University Student eJournal

(C) 2020 under CC BY-NC I ISSN 2369-5617 


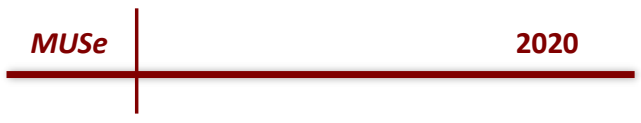

thinkers who changed the way the world is interpreted. The fact that mental illness and significant original creativity frequently coexist is supported in a review of famous European composers, which showed how common it is for mental health problems to be present in those that were most creative (Pucarin-Cvetkovic et al., 2011, p. 1327). Such unique individuals have not only contributed artistically to modern day society but have also brought increasing attention to the outstanding artistic genius that can arise in this context. While there is no suggestion that mental health issues are necessary to be creative, the frequency of such disorders in those that achieve creative originality appears high to some authors. A leading psychiatric authority states that, "the preponderance of the evidence suggests that in creative individuals the rate of mood disorder is high, and [for] clinicians who treat creative individuals with mood disorders [they] must also confront a variety of challenges, including the fear that treatment may diminish creativity" (Andreasen, 2008, p. 251). It has been stated that "to be a serious artist, ... some artists [would] actually mimic madness or eccentricity in order to be more respected for their work" (Sussman, 2007, p. 21). In doing so, these individuals' work was more highly recognized, thus further showing that there has previously been a correlation between mental illness and respected creativity. This can be due to the fact that "features of mental illness may give adaptive advantages to the affected individuals" (Beaussart, Kaufman, \& Kaufman, 2012, p. 153). This potential link between mental health disorders and a putative increase in creativity is certainly provocative.

There is significant literature that identifies that, over thousands of years, there has been a correlation between having a mental disorder and being a more creative individual. The earliest documentation has been dated "as far back as the 4th century B.C." (Sussman, 2007, p. 21). Many correlational studies have been carried out to try and assess the strength of 
this link, including one performed by Dr. Arnold Ludwig, in which he "confirmed that there was a significantly higher prevalence of mental illness in individuals involved in creative pursuits" (Sussman, 2007, p. 22). There is also direct biological evidence that links mental disorders to creativeness. This evidence showed that, in the frontal lobe, where knowledge and concepts are stored, there can be some hyperactivity during mental illness, something which can allow the individual to draw connections between unrelated concepts (Sussman, 2007, p. 22). Furthermore, "activity in this area of the brain is also tied to the neurotransmitter imbalances characteristic of these illnesses" (Sussman, 2007, p. 22). There is further evidence of biological links between these traits showing that "first-degree relatives [are] more likely to be both creative and to be predisposed to mental illness, implying that the two traits are genetically linked" (Sussman, 2007, p. 23). There are also some indirect links between mental disorders and overall creativity. These include illnesses such as schizophrenia that "increase openness, which consequently enhance creativity" (Beaussart et al., 2012, p. 152). Such links also affect an individual's social determinants of health. This can be seen due to the fact that "genetic factors that raise the risk of bipolar disorder and schizophrenia are found more often in people in creative professions. Painters, musicians, writers and dancers were, on average, $25 \%$ more likely to carry the gene variants" (Sample, 2015, para. 4). When taken together, these data sets all show that there are some strongly suggestive links between the presence of mental disorders and having a creative advantage over other individuals.

It is important for individuals suffering from a mental disorder to be provided with therapeutic interventions and coping mechanisms in order to achieve optimum health and optimal creativity. As part of this, creativity (and creative outlets) should be acknowledged and promoted in these patients because it "encourages involvement in (and support of) therapeutic activities, and identifies resources for 


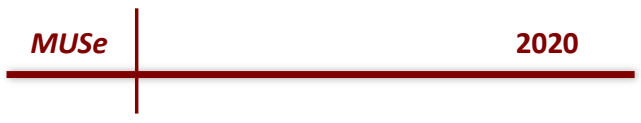

consultation and ongoing support in dealing with the illness" (Herzog \& Varcarolis, 2014, p. 302). For example, "activities such as drawing, reading poetry, and listening to music may be used to focus conversation and promote the recognition and expression of feelings" (Herzog \& Varcarolis, 2014, p. 300). In promoting the use of creativity throughout a patient's subjective illness experience, the individual is able to engage in new therapeutic activities and coping techniques. There is also "evidence that creative writing forms an important part of the recovery experience of people affected by severe mental illnesses" (King, Neilsen, \& White, 2013, p. 444). There are ample examples and ideas for creative techniques to be implemented into patient care, and it is helpful if these techniques are routinely encouraged and promoted to these individuals. In encouraging this form of intervention, the patient "focuses on the need to identify the positive qualities that help individuals to not only overcome problems, but to also go forward and flourish" (Schrank et al., 2014, p. 96). Therefore, there is strong support that the use of creative solutions and inputs can have a meaningful beneficial outcome for patients who have mental health issues, and this information should be more widely known and implemented.

Despite the amount of research that has been carried out, there are clear areas that would benefit from future insights. A reason to further investigate the possible link between mental disorders and creativity is "to gain a deeper understanding of patients' needs and experiences." (Kyaga et al., 2011, p. 373). Detailed links between measurements of creativity and how it is impacted by mental health would benefit these insights. However, there are currently no clearly defined measures of creativity that are available to be utilized in such research (Sussman, 2007, p. 23). Nonetheless, such research in these subjective studies would significantly increase knowledge regarding how creative output and personality positively affect those suffering from mental disorders. Additionally, some 
qualitative research could also be carried out into the lived experiences of these individuals. In terms of actual interventions and possible links to research, these could examine micro nursing interventions with those admitted to hospital with a mental disorder by studying their creative influences during activities such as support groups, art classes, and when interacting with inanimate objects. A macro nursing intervention for patients with mental illness admitted to hospital could be studied, such as the impact of advocating for increased government funding towards creative outlet classes, and support groups, for these patients. Taken together, this information suggests that ongoing research, combined with specific nursing approaches, can enhance outcomes in the short-term and long-term for these patients with mental health issues.

In conclusion, while individuals with mental disorders clearly suffer negative impacts and are often stigmatized, it should be recognized that in certain individuals the presence of such a condition may open opportunities for significant creativity in a variety of areas. Through this, these individuals can find positive outlets to cope better, as well as gain a sense of control and self-efficacy despite their disorders. It may be counter-intuitive to recognize that in individuals with mental health issues there may actually be a greater capacity for creativity than at other times, but such a conclusion does seem to be the direction in which the evidence is currently pointing. Enhancing such understanding, through both education, research, and implementation, may help patients to be better able to become "an active participant in their health care and to engage in holistic practices that can promote health and healing" (Barss, 2014, p. 720).

\section{Acknowledgements}

I would like to especially thank Linda Cook for her endless dedication in promoting, providing, and assisting students in achieving excellence. 


\section{References}

Andreasen, N. C. (2008). The relationship between creativity and mood disorders. Dialogues in Clinical Neuroscience, 10(2), 251-255. Retrieved from http://www.dialogues-cns.org

Barss, K. (2014). Integrative care. In M. Halter, C. Pollard, S. Ray, \& M. Haase (Eds.), Canadian psychiatric mental health nursing: A clinical approach (1st ed., pp. 717734). Toronto, ON: Elsevier Canada.

Beaussart, M., Kaufman, S., \& Kaufman, J. (2012). Creativity, personality, mental illness, and short-term mating success. The Journal of Creative Behaviour, 46(3), 151167. doi: $10.1002 /$ jocb.11

Halter, M., \& Haase, M. (2014). Mental health and illness. In M. Halter, C. Pollard, S. Ray, \& M. Haase (Eds.), Canadian 
psychiatric mental health nursing: A clinical approach (1st ed., pp. 2-16). Toronto, ON: Elsevier Canada.

Herzog, E., \& Varcarolis, E. (2014). Schizophrenia spectrum and other psychotic disorders. In M. Halter, C. Pollard, S. Ray, \& M. Haase (Eds.), Canadian psychiatric mental health nursing: A clinical approach (1st ed., pp. 2-16). Toronto, ON: Elsevier Canada.

King, R., Neilsen, P., \& White, E. (2013). Creative writing in recovery from severe mental illness. International Journal of Mental Health Nursing, 22(5), 444-452. doi: 10.1111/j.1447-0349.2012.00891.x

Kyaga, S., Lichtenstein, P., Boman, M., Hultman, C., Langstrom, N., \& Landen, M. (2011). Creativity and mental disorder: Family study of 300000 people with severe mental disorder. The British Journal of Psychiatry, 199, 373-379. doi: 10.1192/bjp.bp.110.085316

Pucarin-Cvetković, J., Zuskin, E., Mustajbegović, J., JanevHolcer, N., Rudan, P., \& Milosević, M. (2011). Known symptoms and diseases of a number of classical European composers during 17th and 20th century in relation with their artistic musical expressions. Collegium Antropologicum, 35(4), 1327-31. Retrieved from http://www.collantropol.hr/antropo

Sample, I. (2015). New study claims to find genetic link between creativity and mental illness. The Guardian.

Retrieved from http://www.theguardian.com/international

Schrank, B., Brownell, T., Tylee, A., \& Slade, M. (2014). Positive psychology: An approach to supporting recovery in mental illness. East Asian Archives of Psychiatry, 24(4), 95-103. Retrieved from http://easap.asia/index.htm

Sternberg, R., \& Lubart, T. (1996). Investing in creativity. American Psychologist, 51(7), 677-686. Retrieved from http://www.apa.org/pubs/journals/amp/

Sussman, A. (2007). Mental illness and creativity: A neurological view of the "tortured artist". Stanford 
Journal of Neuroscience, 1(1), 21-24. Retrieved from http://web.stanford.edu/group/co-sign/sjnf07.html 